\title{
An easily recoverable and recyclable homogeneous polyester-based Pd catalytic system for the hydrogenation of $\alpha, \beta$-unsaturated carbonyl compounds
}

\author{
Mattia Bartoli a , Luca Rosi ${ }^{\mathrm{a}, \mathrm{b}}$, Giorgio Petrucci ${ }^{\mathrm{a}}$, Lidia Armelao ${ }^{\mathrm{c}}$, Werner Oberhauser ${ }^{\mathrm{d}}$, Marco Frediani ${ }^{\mathrm{a}}$, \\ Oreste Piccolo e,f, Vikas Damu Rathod ${ }^{\mathrm{e}}$, Stefano Paganelli ${ }^{\mathrm{e}, *}$ \\ a Dipartimento di Chimica “Ugo Schiff”, Università degli Studi di Firenze, via della Lastruccia 3-13, Sesto Fiorentino, FI, Italy \\ ${ }^{\mathrm{b}}$ Consorzio Interuniversitario Reattività Chimica e Catalisi (CIRCC), via Celso Ulpiani 27, 70126 Bari, Italy \\ c IENI-CNR and INSTM, Dipartimento di Scienze Chimiche, Università di Padova, Via Marzolo 1, 35131 Padova, Italy \\ d Istituto di Chimica dei Composti OrganoMetallici (ICCOM) CNR, via Madonna del Piano 10, 50019 Sesto Fiorentino, FI, Italy \\ e Dipartimento di Scienze Molecolari e Nanosistemi, Università Ca' Foscari Venezia, via Torino 155, 30170 Venezia Mestre, Italy \\ ${ }^{\mathrm{f}}$ SCSOP, Via Bornò 5, 23896 Sirtori, LC, Italy
}

\section{A R T I C L E I N F O}

\section{Article history:}

Received 23 March 2015

Received in revised form 1 July 2015

Accepted 2 July 2015

Available online 6 July 2015

Keywords:

Hydrogenation

Homogeneous catalysis

Palladium

Macrocomplexes

Polyester

\begin{abstract}
A B S T R A C T
Homogeneous catalysis is an efficient tool to carry out hydrogenation processes but the major drawback is represented by the separation of the expensive catalyst from the product mixture. In this view we prepared a polyester-based Pd catalytic system that offers the advantages of both homogenous and heterogeneous catalyses: efficacy, selectivity and recyclability. Here its application in the hydrogenation of selected $\alpha, \beta$-unsaturated carbonyl compounds is described.
\end{abstract}

(c) 2015 Elsevier B.V. All rights reserved.

\section{Introduction}

The selective hydrogenation of $\alpha, \beta$-unsaturated carbonyl compounds is an important process in the manufacture of some useful fine chemicals as intermediates for the synthesis of pharmaceuticals, additives for food flavors and valuable building blocks for fragrances [1]. The selective reduction of $\alpha, \beta$-unsaturated carbonyl compounds by means of molecular hydrogen in the presence of catalysts still remains an intriguing challenge in catalysis [2]. The selectivity, including enantioselectivity, strongly depends on the nature of the active metal catalyst [3] and on the reaction conditions [4]. Homogeneous catalysts often present good activity and selectivity, but the major drawback of homogeneous processes is the separation of the precious catalyst from the product mixture that requires an energy intensive process such as distillation. Hence several attempts have been accomplished in order to facilitate the separation of the catalyst from the reaction medium like the use of biphasic systems [5] or supported metal complexes [6]. In the realm of Pd-based catalysts the hydrogenation reaction has been carried out in the presence of numerous systems [7]. Interesting

\footnotetext{
* Corresponding author.

E-mail addresses: marco.frediani@unifi.it (M. Frediani), spag@unive.it (S. Paganelli).
}

results have been achieved with polymer-bound palladium complexes in heterogeneous reactions [8-10]. Recently, an innovative approach to recycle a catalytic system has been proposed. It is based on a homogeneous system consisting in a polyester-based Pd-macrocomplex that can be recovered by its precipitation and easy separation from the reaction mixture. The catalyst is prepared by reaction of $\mathrm{Pd}(\mathrm{OAc})_{2}$ with 4-pyridinemethylene-end-capped poly(L-lactide) (macroligand L), as shown in Scheme 1 [11].

The resulting Pd-pyridine poly(L-lactide) macrocomplex, trans$\left[\mathrm{Pd}(\mathrm{OAc})_{2}(\mathrm{~L})_{2}\right]$, has been applied by some of us to catalyze the aerobic oxidation of selected primary and secondary alcohols [12]. Here we report on the capability of trans-[Pd(OAc $\left.)_{2}(\mathrm{~L})_{2}\right]$ to be used as catalyst in the hydrogenation reaction of selected $\alpha, \beta$-unsaturated carbonyl compounds, precisely 2-cyclohexen-1-one (I), (3E)-4-phenylbut-3en-2-one (IV), (3E)-4-(6-methoxy-2-naphthyl)but-3-en-2-one (VII), (2E)-3-phenylprop-2-enal (X) and (2E)-3-(1,3-benzodioxol-5-yil)-2methyl-prop-2-enal (XIII). The macrocomplex is soluble under the applied catalytic conditions but, upon addition of a hydrocarbon solvent or preferably methanol, the polymer-anchored Pd catalyst precipitates allowing the separation from the reaction solution and, thus, it is easily recyclable. This system therefore combines the activity and selectivity of a homogeneous catalyst with the easy recovery and recyclability of a 


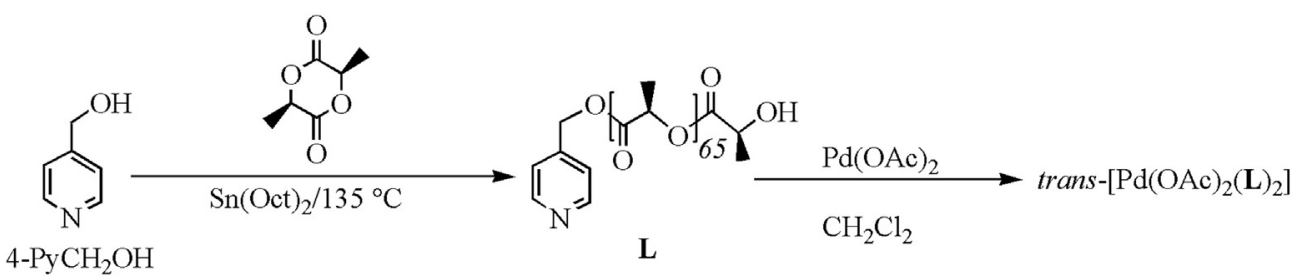

Scheme 1. Synthesis of trans- $\left[\mathrm{Pd}(\mathrm{OAc})_{2}(\mathbf{L})_{2}\right]$.

heterogeneous one without making any change to the catalyst structure.

\section{Experimental}

\subsection{Materials}

2-Cyclohexen-1-one, (3E)-4-phenylbut-3-en-2-one, (2E)-3phenylprop-2-enal, 4-pyridinemethanol, dry $\mathrm{CH}_{2} \mathrm{Cl}_{2}$, pyridine and $\mathrm{Pd}(\mathrm{OAc})_{2}$ were Aldrich products. (3E)-4-(6-methoxy-2-naphthyl)but3-en-2-one was a generous gift from Chemi SpA. (2E)-3-(1,3benzodioxol-5-yil)-2-methyl-prop-2-enal was synthesized as described in the literature [13]. Starting materials for the synthesis of the macroligand $\mathbf{L}$ and trans- $\left[\mathrm{Pd}(\mathrm{OAc})_{2}(\mathrm{~L})_{2}\right]$ were Purac products. $\mathrm{Pd}(\mathrm{II})$ pyridine poly(L-lactide) macrocrocomplex, trans-[Pd(OAc $\left.)_{2}(\mathrm{~L})_{2}\right]$, was synthesized and characterized as described by Giachi et al. [11] (see Supplementary content). GC analyses were carried out on an Agilent 6850 A gas chromatograph (HP1 column $30 \mathrm{~m} \times 0.32 \mathrm{~mm} \times 0.25 \mu \mathrm{m}$ ) and GC-MS analyses were performed by using an Agilent MS Network

Table 1

Hydrogenation of 2-cyclohexen-1-one (I) catalyzed by Pd-catalysts.

\begin{tabular}{|c|c|c|c|c|c|}
\hline Entry & Pre-catalyst or catalyst & $\mathrm{t}(\mathrm{h})$ & Conversion $(\%)^{\mathrm{a}}$ & II yield (\%) & III yield (\%) \\
\hline $1^{\mathrm{b}}$ & $\mathrm{Pd}(\mathrm{OAc})_{2}$ & 1 & 95 & 95 & nd \\
\hline $2^{\mathrm{b}}$ & $\mathrm{Pd}(\mathrm{OAc})_{2} / \mathrm{Py}(1 / 2)$ & 3 & 65 & 65 & nd \\
\hline 3 & $\mathrm{Pd}(\mathrm{OAc})_{2} / \mathrm{TBAB}$ & 3 & 20 & 20 & nd \\
\hline 4 & trans $-\left[\mathrm{Pd}(\mathrm{OAc})_{2}(\mathrm{~L})_{2}\right]$ & 1 & 30 & 30 & nd \\
\hline $5^{c}$ & {$[\mathrm{Pd}](\mathrm{L})_{2}$} & 1 & 37 & 37 & nd \\
\hline $6^{c}$ & {$[\mathrm{Pd}](\mathrm{L})_{2}$} & 1 & 35 & 35 & nd \\
\hline 7 & trans $-\left[\mathrm{Pd}(\mathrm{OAc})_{2}(\mathrm{~L})_{2}\right]$ & 2 & 70 & 70 & nd \\
\hline 8 & trans $-\left[\mathrm{Pd}(\mathrm{OAc})_{2}(\mathrm{~L})_{2}\right]$ & 3 & $>99$ & $>99$ & nd \\
\hline $9^{c}$ & {$[\mathrm{Pd}](\mathrm{L})_{2}$} & 3 & $>99$ & $>99$ & nd \\
\hline $10^{c}$ & {$[\mathrm{Pd}](\mathrm{L})_{2}$} & 3 & $>99$ & $>99$ & nd \\
\hline $11^{\mathrm{c}}$ & {$[\mathrm{Pd}](\mathrm{L})_{2}$} & 3 & $>99$ & $>99$ & nd \\
\hline
\end{tabular}

Reaction conditions: substrate $=10.5 \mathrm{mmol}$; substrate $/$ Pd (molar ratio) $=1000 / 1$ toluene $=10 \mathrm{~mL} ; \mathrm{p}\left(\mathrm{H}_{2}\right)=0.1 \mathrm{MPa} ; \mathrm{T}=30^{\circ} \mathrm{C} ; \mathrm{TBAB}=$ tetrabutylammonium bromide; $\mathrm{Py}=$ pyridine. $\mathrm{nd}=$ not detected in the reaction mixture.

a Determined by GC (n-dodecane as internal standard).

b Pd black was formed.

c Reaction carried out by using the catalytic palladium species trans-[ $\left.\mathrm{Pd}(\mathrm{OAc})_{2}(\mathrm{~L})_{2}\right]$, indicated as $[\mathrm{Pd}](\mathrm{L})_{2}$, recovered from the previous run.

Table 2

Hydrogenation of (3E)-4-phenylbut-3-en-2-one (IV) catalyzed by trans-[Pd( $\left.\mathrm{OAc})_{2}(\mathrm{~L})_{2}\right]$.

\begin{tabular}{lllll}
\hline Entry & $\mathrm{t}(\mathrm{h})$ & Conversion $(\%)^{\mathrm{a}}$ & $\mathbf{V}$ yield $(\%)$ & VI yield $(\%)$ \\
\hline 1 & 1 & 20 & 20 & nd \\
2 & 3 & $>99$ & $>99$ & nd \\
$3^{\mathrm{b}}$ & 3 & $>99$ & $>99$ & nd \\
$4^{\mathrm{b}}$ & 3 & $>99$ & $>99$ & nd \\
$5^{\mathrm{b}}$ & 3 & $>99$ & $>99$ & nd \\
$6^{\mathrm{c}}$ & 3 & 39 & 39 & nd \\
\hline
\end{tabular}

Reaction conditions: substrate $=5.6 \mathrm{mmol}$; substrate $/ \mathrm{Pd}($ molar ratio $)=1000 / 1$; toluene $=10 \mathrm{~mL} ; \mathrm{p}\left(\mathrm{H}_{2}\right)=0.1 \mathrm{MPa} ; \mathrm{T}=30^{\circ} \mathrm{C}$. nd = not detected in the reaction mixture.

a Determined by GC (n-dodecane as internal standard).

b Reaction carried out by using the catalyst recovered from the previous run.

c Experiment carried out by using $25 \mathrm{ml}$ of toluene instead of $10 \mathrm{ml}$.
5937 (HP-5MS column $30 \mathrm{~m} \times 0.25 \mathrm{~mm} \times 0.25 \mu \mathrm{m}$ ). ${ }^{1} \mathrm{HNMR}$ analyses were performed by using a GEMINI $400 \mathrm{MHz}$ using $\mathrm{CDCl}_{3}$ (Aldrich). GPC analyses were carried out with Waters mod. binary HPLC 1525 equipped with three columns (Shodex KF802.5, KF-803, KF-804) and a refractive index detector Wyatt T-REX optilab. Analyses were performed with THF (Chromasolv, HPLC-grade $\geq 99.8 \%$ ). ICP analysis was performed by "Laboratorio di Microanalisi" of Chemistry Department of University of Florence. XPS analysis was run on a Perkin-Elmer $\Phi$ 5600 -ci spectrometer using non-monochromatized $\mathrm{Al} \mathrm{K}_{\alpha}$ radiation $(1486.6 \mathrm{eV})$. The sample analysis area was $800 \mu \mathrm{m}$ in diameter and the working pressure was lower than $10^{-9}$ mbar. The spectrometer was calibrated by assuming the binding energy ( $\mathrm{BE}$ ) of the $\mathrm{Au} 4 \mathrm{f}_{7 / 2}$ line at $83.9 \mathrm{eV}$ with respect to the Fermi level. The standard deviation for the BEs values was $\pm 0.2 \mathrm{eV}$. Survey scans were obtained in the $0-1300 \mathrm{eV}$ range (187.8 eV pass energy, $0.4 \mathrm{eV} \mathrm{step}^{-1}, 0.05 \mathrm{~s} \mathrm{step}^{-1}$ ). Detailed scans were recorded for the $\mathrm{C} 1 \mathrm{~s}, \mathrm{O} 1 \mathrm{~s}, \mathrm{~N} 1 \mathrm{~s}$ and Pd3d regions ( $23.5 \mathrm{eV}$ pass energy, $0.1 \mathrm{eV} \mathrm{step}^{-1}, 0.1 \mathrm{~s} \mathrm{step}^{-1}$ ). No further element was detected. The BE shifts were corrected by assigning to the $\mathrm{C} 1 \mathrm{~s}$ peak associated with adventitious hydrocarbons a value of $284.8 \mathrm{eV}$ [14]. Samples were mounted on steel holders and introduced directly in the fast-entry lock system of the XPS analytical chamber. The analysis involved Shirley-type background subtraction, non-linear least-squares curve fitting adopting Gaussian-Lorentzian peak shapes, and peak area determination by integration [15]. The atomic compositions were evaluated from peak areas using sensitivity factors supplied by PerkinElmer, taking into account the geometric configuration of the apparatus [16]. Analysis was performed on different sample portions in order to check for chemical homogeneity.

\subsection{General procedure for hydrogenation experiments}

All the reactions were carried out following a procedure similar to that below described for the polyester-based Pd catalyzed hydrogenation of (2E)-3-phenylprop-2-enal (X). Experimental details, different for every substrate, are reported in Tables $1-5$.

A $150-\mathrm{mL}$ stainless steel reaction vessel was charged, under a nitrogen purge, with $396 \mathrm{mg}$ (3 mmol) of X, $26.7 \mathrm{mg}$ of trans-[Pd( $\left.\mathrm{OAc})_{2}(\mathrm{~L})_{2}\right]$ (corresponding to $0.003 \mathrm{mmol}$ of Pd) and $10 \mathrm{~mL}$ of toluene. The reactor was then pressurized with $0.2 \mathrm{MPa}$ of hydrogen and heated at $30^{\circ} \mathrm{C}$ for $6 \mathrm{~h}$ (Table 4). The reactor was then cooled to room temperature, the

Table 3

Hydrogenation of (3E)-4-(6-methoxy-2-naphthyl)but-3-en-2-one (VII) catalyzed by trans- $\left[\mathrm{Pd}(\mathrm{OAc})_{2}(\mathrm{~L})_{2}\right]$.

\begin{tabular}{llrlll}
\hline Entry & $\mathrm{P}\left(\mathrm{H}_{2}\right)(\mathrm{MPa})$ & $\mathrm{t}(\mathrm{h})$ & ${\text { Conversion }(\%)^{\mathrm{a}}}^{\mathrm{a}}$ & VIII yield $(\%)$ & IX yield $(\%)$ \\
\hline 1 & 0.1 & 3 & 2 & 2 & nd \\
2 & 0.1 & 24 & 57 & 57 & nd \\
3 & 1 & 3 & 15 & 15 & nd \\
4 & 2 & 3 & 44 & 44 & nd \\
5 & 2 & 5 & 56 & 54 & 2 \\
$6^{\text {b }}$ & 2 & 5 & 52 & 51 & 1 \\
$7^{\text {b }}$ & 2 & 5 & 55 & 54 & 1 \\
$8^{\text {b }}$ & 2 & 5 & 52 & 52 & nd \\
\hline
\end{tabular}

Reaction conditions: substrate $=5.5 \mathrm{mmol}$; substrate $/$ Pd $($ molar ratio $)=1000 / 1$; $\mathrm{T}=30{ }^{\circ} \mathrm{C}$; toluene $=25 \mathrm{~mL}$. nd $=$ not detected in the reaction mixture

a Determined by GC (n-dodecane as internal standard).

b Reaction carried out by using the catalyst recovered from the previous run. 
Table 4

Hydrogenation of (2E)-3-phenylprop-2-enal $(\mathbf{X})$ catalyzed by trans- $\left[\mathrm{Pd}(\mathrm{OAc})_{2}(\mathrm{~L})_{2}\right]$.

\begin{tabular}{lllcccl}
\hline Entry & $\mathrm{T}\left({ }^{\circ} \mathrm{C}\right)$ & $\mathrm{P}\left(\mathrm{H}_{2}\right)(\mathrm{MPa})$ & $\mathrm{t}(\mathrm{h})$ & Conversion $(\%)^{\mathrm{a}}$ & XI yield $(\%)$ & XII yield $(\%)$ \\
\hline 1 & 30 & 0.1 & 6 & 9 & 9 & $\mathrm{nd}$ \\
2 & 30 & 0.1 & 24 & 96 & 90 & 6 \\
$3^{\mathrm{b}}$ & 60 & 0.1 & 6 & 70 & 35 & 35 \\
4 & 30 & 2 & 6 & 96 & 91 & 5 \\
$5^{\mathrm{c}}$ & 30 & 2 & 6 & $>99$ & 95 & 5 \\
$6^{\mathrm{c}}$ & 30 & 2 & 6 & $>99$ & 95 & 5 \\
$7^{\mathrm{c}}$ & 30 & 2 & 6 & $>99$ & 95 & 5 \\
\hline
\end{tabular}

Reaction conditions: substrate $=3 \mathrm{mmol}$; substrate $/ \mathrm{Pd}($ molar ratio $)=1000 / 1$; toluene $=10 \mathrm{~mL}$. nd $=$ not detected in the reaction mixture.

a Determined by GC (n-dodecane as internal standard).

b Pd black was formed.

c Reaction carried out by using the catalyst recovered from the previous run. residual gases released and the reaction mixture analyzed by GC and GC-MS. Methanol was then added to the reaction mixture until complete precipitation of the polyester-based Pd-catalyst that was recovered by filtration, dried under vacuum and reused in a recycling experiment.

Compound II, GC-MS m/z: 98, 69, 55, 42.

Compound V, GC-MS m/z: 148, 133, 105, 91, 77, 43.

Compound VIII, GC-MS m/z: 228, 171, 141, 115.

Compound IX, GC-MS m/z: 230, 212, 197, 172, 141, 115.

Compound XI, GC-MS m/z: 134, 105, 91, 78.

Compound XII, GC-MS m/z: 136, 118, 105, 91, 77.

Compound XIV, GC-MS m/z: 192, 135, 122, 105, 77, 51.

Compound XV, GC-MS m/z: 194, 176, 135, 77, 51.

\section{Results and discussion}

\subsection{Catalyst stability}

The behavior of the complex trans- $\left[\mathrm{Pd}(\mathrm{OAc})_{2}(\mathrm{~L})_{2}\right]$ has been studied by ${ }^{1} \mathrm{HNMR}$ spectroscopy, ICP and XRD analysis. ${ }^{1} \mathrm{HNMR}$ was a useful technique to study this system (Fig. 1). The formation of trans$\left[\mathrm{Pd}(\mathrm{OAc})_{2}(\mathbf{L})_{2}\right]$ was confirmed by changing in chemical shift $(\delta)$ of aromatic hydrogen signals of $\mathbf{L}$ (8.68 ortho- $\mathrm{H}$ and 7.46 meta-H ppm, trace A) to different $\delta$ ( 8.79 ortho- $\mathrm{H}, 8.67$ meta-H ppm, trace B). After three catalytic runs no evidence of palladium nanoparticles (signals at 8.82 ortho-H, 8.62 meta-H ppm, trace D) were detected. The pattern of signals of trans- $\left[\mathrm{Pd}(\mathrm{OAc})_{2}(\mathbf{L})_{2}\right]$ was changed (8.82 ortho- $\mathrm{H}, 7.58$ meta-H ppm, trace $\mathbf{C})$. Probably this was due to the formation, after work up, of palladium(II) species, like palladium oxides, still bound

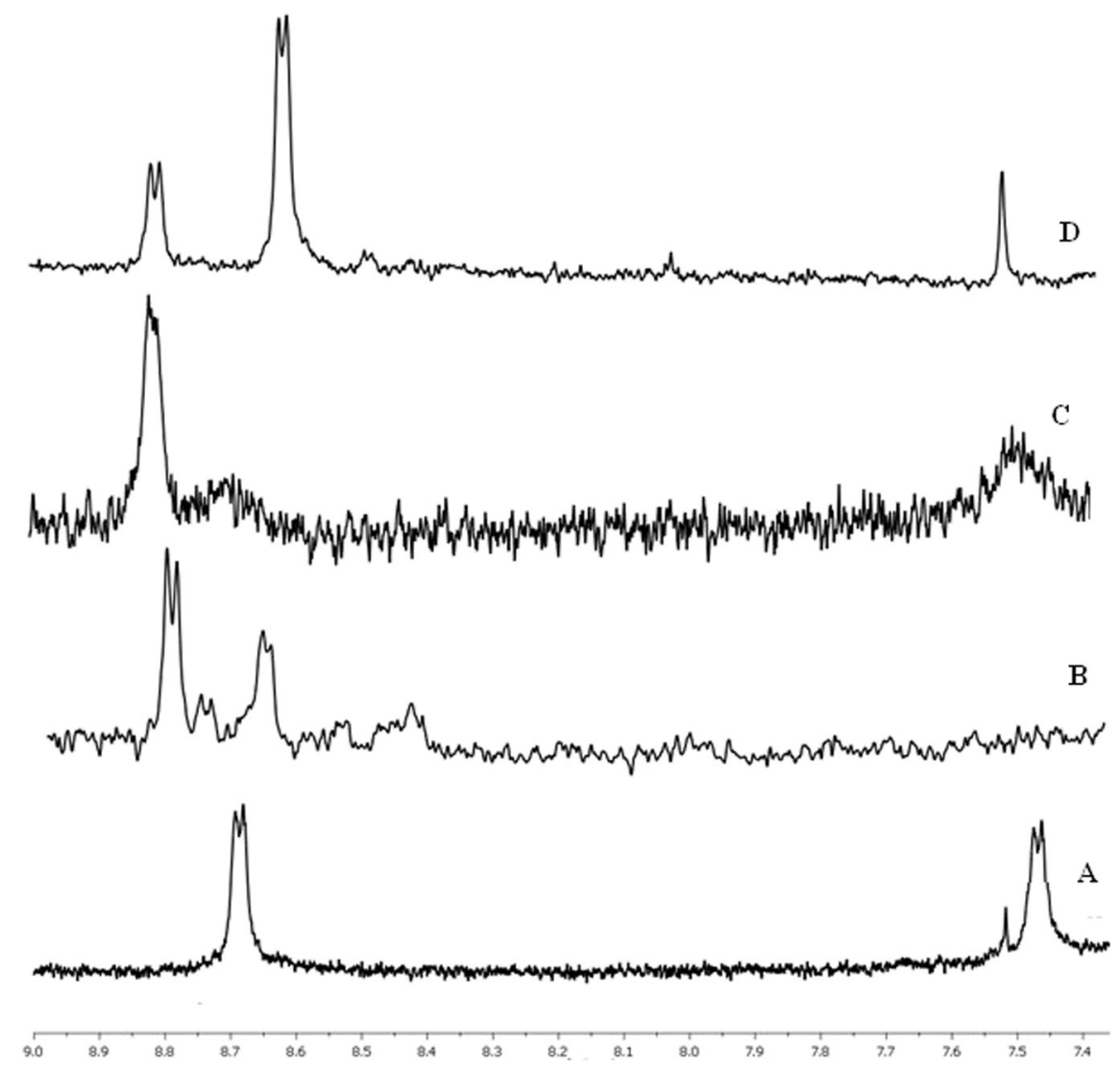

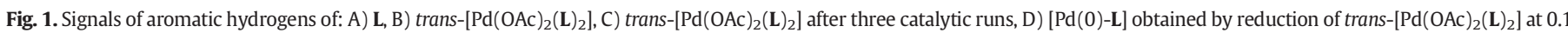
Mpa of $\mathrm{H}_{2}$ and $60{ }^{\circ} \mathrm{C}$ for $6 \mathrm{~h}$. 
to $\mathbf{L}$. Moreover, ICP analysis showed only a $0.36 \%$ loss of palladium ( $\mathrm{mol} / \mathrm{mol}$ ) after the first catalytic run (2-cyclohexen-1-one (I) hydrogenation, $3 \mathrm{~h}, 30{ }^{\circ} \mathrm{C}$ and $\left.\mathrm{P}\left(\mathrm{H}_{2}\right)=0.1 \mathrm{MPa}\right)$.

XPS investigation was performed on the fresh catalyst and after the first catalytic run (2-cyclohexen-1-one hydrogenation, $3 \mathrm{~h}, 30{ }^{\circ} \mathrm{C}$ and $\left.\mathrm{P}\left(\mathrm{H}_{2}\right)=0,1 \mathrm{MPa}\right)$ in order to evaluate its chemical composition before and after the hydrogenation reaction. In both cases, the expected elements, i.e. palladium, nitrogen, carbon, and oxygen were found. Fig. 2A shows the XPS spectra related to the Pd3d regions before (continuous line) and after (dotted line) the hydrogenation process and work-up. Similar features for the peaks were observed, suggesting an alike electronic environment around palladium in the fresh catalyst and after the reaction and recovery. In particular, both spectra are composed of a doublet corresponding to the emission from the spin-orbit split $3 \mathrm{~d}_{5 / 2}$ and $3 \mathrm{~d}_{3 / 2}$ core levels. The corresponding binding energy peaks positions at 337.1 and $342.2 \mathrm{eV}$ are assigned to divalent $\mathrm{Pd}^{2+}$ ions in palladium compounds [17]. Therefore, the interpretation of the Pd3d spectra indicates that palladium, which is reduced under the catalytic conditions, is however reoxidized, during the work-up and recovery, probably for the action of air $[18,19]$. Regarding the C1s line, a complex shape profile is found with the presence of at least three different carbon-related contributions, as shown in Fig. 2B. Peak fitting revealed three components centered at binding energies (BE) $284.8 \mathrm{eV}$ $\left(\mathrm{C}_{\mathrm{I}}\right), 286.8 \mathrm{eV}\left(\mathrm{C}_{\mathrm{II}}\right)$ and $288.7 \mathrm{eV}\left(\mathrm{C}_{\mathrm{III}}\right)$. According to the chemical structure of the palladium macrocycle, the dominant lower energy component $\left(C_{I}\right)$ can be ascribed to aliphatic carbon; a second component $\left(\mathrm{C}_{\mathrm{II}}\right)$ at higher $\mathrm{BE}$ can be associated to oxygen-bound carbon; a third component $\left(\mathrm{C}_{\mathrm{III}}\right)$ at even higher $\mathrm{BE}$ that can be coherently assigned to the electron-depleted carboxylic carbon.

\subsection{Catalytic experiments}

A first set of hydrogenation experiments was carried out on 2-cyclohexen-1-one (I) as the substrate (Scheme 2), by using a $1000 / 1$ substrate to catalyst molar ratio and under $0.1 \mathrm{MPa}_{2}$ : after $1 \mathrm{~h}$ at $30{ }^{\circ} \mathrm{C}$ cyclohexanone (II) was obtained with $30 \%$ yield (entry 4 , Table 1). Upon prolonging the reaction time up to $3 \mathrm{~h}, 100 \%$ of both conversion and selectivity to II was achieved (Entry 8, Table 1). After each experiment the catalytic system was precipitated by simply adding methanol to the solution. The catalyst was then filtered, dried under vacuum and reused in a consecutive experiment: noteworthy, the catalytic activity and selectivity to cyclohexanone (II) remained unchanged even after three recycling experiments (entries 9-11, Table 1). As trans$\left[\mathrm{Pd}(\mathrm{OAc})_{2}(\mathbf{L})_{2}\right]$ was synthesized from $\mathrm{Pd}(\mathrm{OAc})_{2}$ and the polylactide ligand $(\mathbf{L})$, a reaction was carried out in the presence of $\operatorname{Pd}(\mathrm{OAc})_{2}$ alone without any external ligand and in the same experimental conditions, in order to make a comparison of the two systems: cyclohexanone (II) was obtained with a 95\% yield already after $1 \mathrm{~h}$, but the catalyst decomposed with formation of an unsoluble and catalytically inactive Pd black, not suitable for any recycle (entry 1 , Table 1 ). Also carrying out the reaction at the same reaction conditions but in the presence of pyridine (Py) as external ligand ( $\mathrm{Pd} / \mathrm{Py}=1 / 2$ molar ratio), $65 \%$ of cyclohexanone (II) was formed but again Pd black was observed in the mixture (entry 2, Table 1 ). Furthermore, in an experiment carried out in the presence of $\mathrm{Pd}(\mathrm{OAc})_{2}$ and tetrabutylammonium bromide as the ligand [20], the conversion was only $20 \%$ (run 3, Table 1 ) after $3 \mathrm{~h}$, so evidencing the good performance of the polyester-based Pd catalyst.

The polyester-based Pd catalyst showed good activity also in the hydrogenation of (3E)-4-phenylbut-3-en-2-one (IV) (Scheme 3a, Table 2). In this case $\mathbf{V}$ was quantitatively obtained, as the sole reaction product, after $3 \mathrm{~h}$ at $30^{\circ} \mathrm{C}$, under $0.1 \mathrm{MPa}$ of $\mathrm{H}_{2}$ and by using a $1000 / 1$ substrate/Pd molar ratio. The catalyst, recovered by adding methanol to the reaction mixture, was used in three successive experiments in which it showed unchanged activity and selectivity (entries 2-5, Table 2).
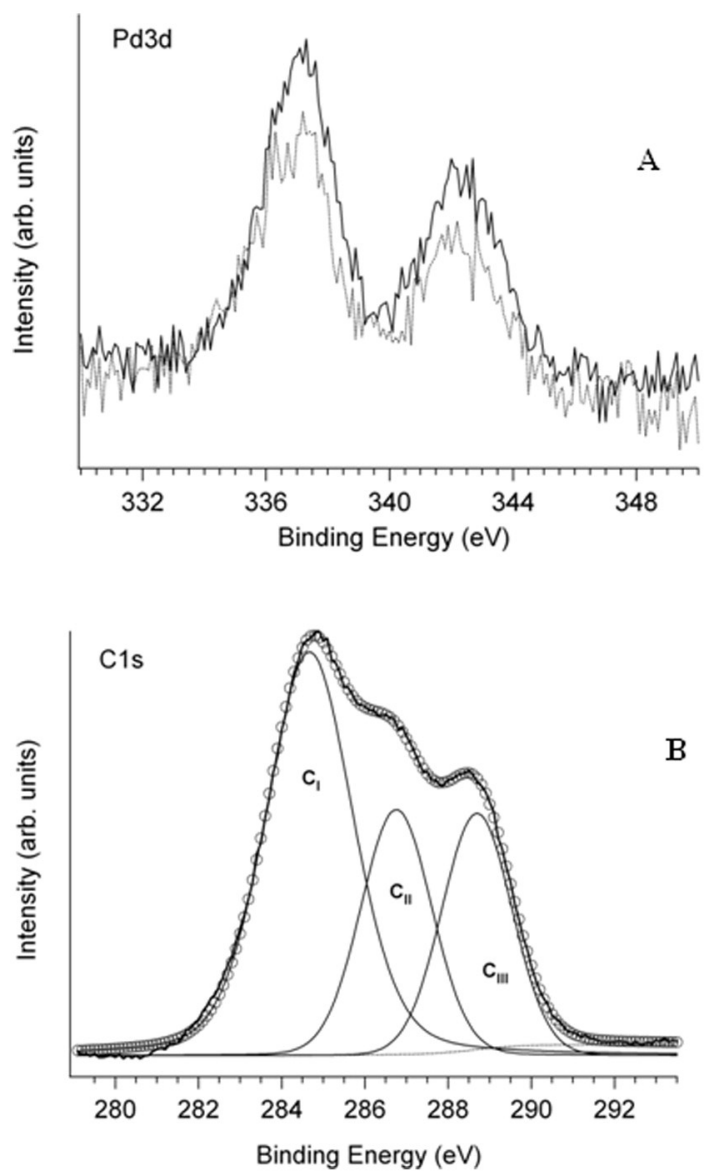

Fig. 2. A) High resolution XPS spectra of the Pd3d regions before (continuous lines) and after (dotted lines) the catalytic process. B) High resolution XPS spectrum of the C1s region before the hydrogenation process. The fitting components of the peak are also reported. The same profile is observed after reaction.

Once aware of the capability of the catalyst to hydrogenate selectively the $\mathrm{C}=\mathrm{C}$ double bond, some hydrogenation experiments on the $\alpha, \beta$-unsaturated ketone VII, a valuable precursor of Nabumetone (VIII), a nonsteroidal anti-inflammatory, analgesic and antipyretic drug (Scheme 3b, Table 3) were carried out. Many synthetic procedures to prepare Nabumetone are described in the literature and all of them involve the selective hydrogenation of the carbonyl conjugated $\mathrm{C}=\mathrm{C}$ double bond [21]. Usually, heterogeneous catalysts as Pd/C, Ni Raney [22], $\mathrm{Rh} / \mathrm{Al}_{2} \mathrm{O}_{3}$ [23] and $\mathrm{Cu} / \mathrm{SiO}_{2}$ [24] are employed, and in some cases, when the catalyst is Pd, its pre-activation or the use of a base is necessary to obtain good selectivity [21]. The hydrogenation of VII was studied at different $\mathrm{H}_{2}$ pressures and reaction times, while keeping constant at $30{ }^{\circ} \mathrm{C}$ the temperature and with a substrate to catalyst molar ratio of $1000 / 1$. A first experiment carried out at $0.1 \mathrm{MPa}$ of $\mathrm{H}_{2}$ for $3 \mathrm{~h}$ gave a very low conversion to VIII. However, on increasing both pressure and reaction time ( $2 \mathrm{Mpa}, 5 \mathrm{~h}$ ) a $56 \%$ conversion was obtained; in this case also $2 \%$ of alcohol IX was formed (entry 5 , Table 3 ). By comparing these results with those obtained with the structurally related IV, a sharp decrease of the reaction rate can be observed. The lower activity

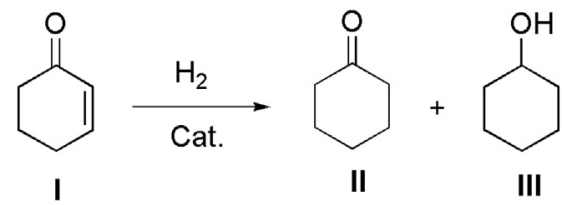

Scheme 2. Hydrogenation of 2-cyclohexen-1-one (I). 
of the catalyst with respect to the reaction on IV should be ascribed to the high dilution of the reaction, due to the low solubility of the substrate in the solvent employed. As a matter of fact, when the reaction was carried out on ketone IV by using $25 \mathrm{ml}$ of toluene instead of $10 \mathrm{ml}$, conversion, after $3 \mathrm{~h}$, was only 39\% instead of $100 \%$ (entry 6 , Table 2). The catalyst, recovered as above described, was reused in three consecutive recycling experiments and its activity remained practically unchanged. Noteworthy the selectivity to VIII was always very high, ranging from 96 to $100 \%$.

Interesting results were obtained also in the hydrogenation of (2E)3-phenylprop-2-enal (X) (Scheme 3c, Table 4). Initially $\mathbf{X}$ was hydrogenated in the presence of the polyester-based Pd catalyst by using a $1000 / 1$ substrate to Pd molar ratio, at $30^{\circ} \mathrm{C}$ and $0.1 \mathrm{MPa}$ of $\mathrm{H}_{2}$ for $6 \mathrm{~h}$, obtaining a very low conversion to 3-phenylpropanal (XI) (9\%) (entry 1 , Table 4). When the reaction time was prolonged to $24 \mathrm{~h}$, a $96 \%$ conversion was achieved but also a small amount (6\%) of alcohol XII was recovered (entry 2 , Table 4 ). When the reaction temperature was increased to $60{ }^{\circ} \mathrm{C}$ the conversion rose to $70 \%$ in $6 \mathrm{~h}$ but in detriment of selectivity, since $\mathbf{X I}$ and $\mathbf{X I I}$ were also produced in equal amount (entry 3, Table 4); moreover, in these conditions, the catalyst was not stable and Pd black was formed. A very good conversion (96\%) was obtained at $30^{\circ} \mathrm{C}$ and $2 \mathrm{MPa}$ of $\mathrm{H}_{2}$ for $6 \mathrm{~h}$, maintaining a substrate to $\mathrm{Pd}$ molar ratio 1000/1: XI was the prevailing product being the alcohol XII formed in small amount (5\%) (entry 4, Table 4). The recovered catalyst maintained a very good activity also in three recycling experiments affording complete conversions and 95\% selectivity to the saturated aldehyde XI (entries 5-7, Table 4).

As an application of the described catalytic system, the hydrogenation of 3-(1,3-benzodioxol-5-yil)-2-methyl-propenal (XIII), an $\alpha, \beta$-unsaturated aldehyde precursor of Helional ${ }^{\circledR}(\mathbf{X I V})$, a valuable fragrance used in both feminine and masculine perfumes [13,25-34], was studied (Scheme 3d, Table 5). A first experiment carried out at $30{ }^{\circ} \mathrm{C}$ and $0.2 \mathrm{MPa}$ of $\mathrm{H}_{2}$ for $3 \mathrm{~h}$ and using a 1000/1 substrate to $\mathrm{Pd}$ molar ratio gave a very disappointing result (conversion 5\%) (entry 1 , Table 5). Increasing the substrate/Pd ratio to $100 / 1$, conversion rose up to $28 \%$ after $2 \mathrm{~h}$, but despite the improvement in conversion the selectivity was still very unsatisfactory as both XIV and the corresponding alcohol $\mathbf{X V}$ were formed (entry 2, Table 5). A complete conversion was obtained at $30{ }^{\circ} \mathrm{C}$ and $0.5 \mathrm{MPa}$ of $\mathrm{H}_{2}$ for $7 \mathrm{~h}$ : XIV was formed but the major product was XV (67\%) (entry 3, Table 5). The catalyst was recycled in three consecutive experiments but even if conversions were always very high a certain deactivation of the catalyst occurred, so showing a decreased ability to hydrogenate the carbonyl group (entries 4-6, Table 5). Noteworthy, the catalyst showed a lower activity with respect to $\mathbf{X}$ : surely, the presence of the methyl group in $\alpha$-position to the carbonyl group makes more difficult the coordination of Pd to the sterically hindered trisubstituted $\mathrm{C}=\mathrm{C}$ double bond. Moreover, the high dilution could strongly influence the reaction rate analogously to that hypothesized for the hydrogenation of ketone VII.

\subsubsection{Homogeneity test}

When transition-metal complexes are used as precatalysts in hydrogenation processes it is important to establish the nature of the active species. The true catalyst may be a homogeneous metal complex or active metal particles present in solutions as colloids or metal nanoclusters, formed under reaction conditions. $\mathrm{As} \mathrm{Hg}(0)$ is able to poison heterogeneous (colloidal or nanoparticulate) metal catalysts while it does not deactivate true homogeneous metal complexes, we carried out the hydrogenation of 2-cyclohexen-1-one (I) at $0.1 \mathrm{MPa}$ of $\mathrm{H}_{2}$ and $30^{\circ} \mathrm{C}$ for $3 \mathrm{~h}$ in the presence of $\mathrm{Hg}(0)$, according to a procedure described in the literature [35]. The catalytic activity remained unchanged, so indicating that it is due most likely to an homogeneous metal complex.

\section{Conclusions}

Pyridine poly(L-lactide)-based Pd macrocrocomplex, trans$\left[\mathrm{Pd}(\mathrm{OAC})_{2}(\mathrm{~L})_{2}\right]$, has showed an interesting activity and good recyclability in the hydrogenation of some $\alpha, \beta$-unsaturated carbonyl compounds. Its selectivity may be strongly affected by the substrate shape. In fact for substrates I, IV, VII and $\mathbf{X}$ the corresponding saturated carbonyl compounds are formed with comparable or higher selectivity

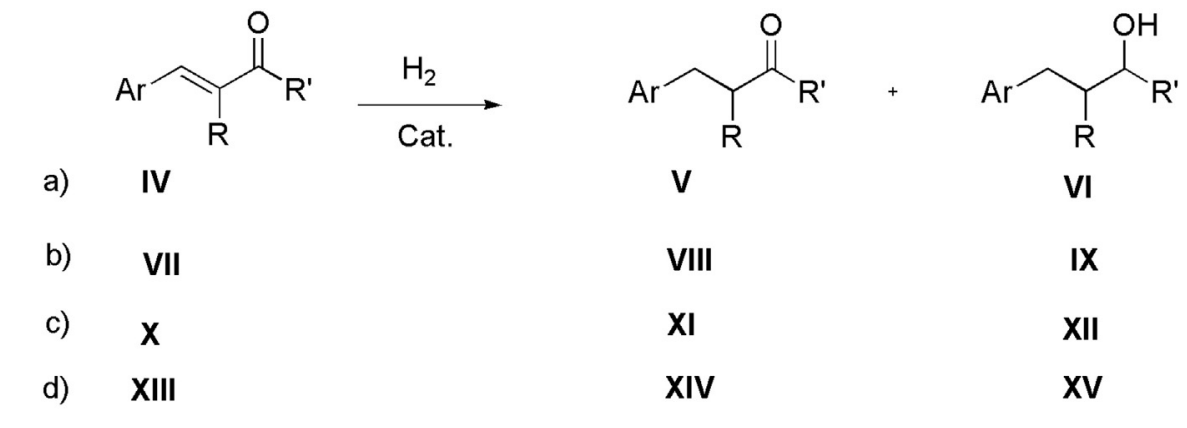

a) $\mathrm{Ar}$

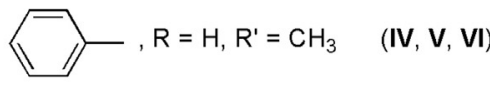

b) $\mathrm{Ar}=$<smiles>[R]=C=[R]</smiles>

(VII, VIII, IX)

c) $\mathrm{Ar}=$<smiles>P=[Ru]c1ccccc1</smiles>

$(\mathrm{X}, \mathrm{XI}, \mathrm{XII})$

d) $\mathrm{Ar}=\mathrm{C}, \mathrm{R}=\mathrm{CH}_{3}, \mathrm{R}^{\prime}=\mathrm{H}$

(XIII, XIV, XV) 
than other palladium catalysts [35]; only by forcing the reaction conditions the saturated alcohols IX and XII are produced, even if, in most cases, in almost negligible amounts. On the contrary a mixture of saturated carbonyl compound $\mathbf{X I V}$ and saturated alcohol $\mathbf{X V}$ is obtained by hydrogenation of substrate XIII. This fact is justified, according to us, by steric reasons, the methyl group in $\alpha$ position in this unsaturated aldehyde being able to affect negatively the interaction between $\mathrm{C}=\mathrm{C}$ bond with this hindered Pd species and positively its interaction with $\mathrm{C}=\mathrm{O}$. Noteworthy, in all the hydrogenation experiments, whatever the unsaturated carbonyl compound tested, the corresponding allylic alcohol has never been detected in the reaction mixture. It is to point out that this homogeneous catalyst is easily separated from the reaction mixture by simple addition of methanol to the reaction mixture and the recovered catalytic system maintains a good activity and selectivity also in recycling experiments. Considering both the data collected and the easy recyclability, this homogeneous catalytic species is a promising and peculiar catalyst for the hydrogenation of $\alpha, \beta$-carbonyl compounds. Moreover, the catalyst was substantially unmodified after catalytic runs and recovery as shown by ICP, XRPD, XPS and ${ }^{1} \mathrm{HNMR}$ analysis.

\section{References}

[1] B. Chen, U. Dingerdissen, J.G.E. Krauter, H.G.J. Lansink Rotgerink, K. Mobus, D.J. Ostgard, P. Panster, T.H. Riermeier, S. Seebald, T. Tacke, H. Trauthwein, Appl. Catal. A Gen. 280 (2005) 17-46.

[2] A. Stolle, T. Gallert, C. Schmögera, B. Ondruschkaa, RSC Adv. 3 (2013) 2112-2153.

[3] J.M. Grosselin, C. Mercier, G. Allmag, F. Grass, Organometallics 10 (1991) 2126-2133.

[4] Q.-A. Chen, Z.-S. Ye, Y. Duan, Y.-G. Zhou, Chem. Soc. Rev. 42 (2013) 497-511.

[5] B. Cornils, W.A. Herrmann, I.T. Horvath, W. Leitner, S. Mecking, H. Olivier-Bourbigou, D. Vogt (Eds.), Multiphase Homogeneous Catalysis, Wiley-VCH, Weinheim, 2005.

[6] C.H. Bartholomew, R.J. Farrauto (Eds.), Fundamentals of Industrial Catalytic Processes, 2nd ed.Wiley, Hoboken, 2006.

[7] E. Negishi (Ed.), Handbook of Organopalladium Chemistry for Organic Synthesis, Wiley, Hoboken, 2002.

[8] M.M. Dell'Anna, J. Mol. Catal. A Chem. 158 (2000) 515-520.

[9] M. Islam, P. Mondal, A. Singha Roy, K. Tuhina, J. Mater. Sci. 45 (2010) 2484-2493.
[10] D. Astruc, F. Lu, J. Ruiz Aranzaes, Angew. Chem. Int. Ed. 44 (2005) 7852-7872

[11] G. Giachi, M. Frediani, W. Oberhauser, E. Passaglia, Polym. Chem. 49 (2011) 4708-4713.

[12] G. Giachi, M. Frediani, W. Oberhauser, E. Passaglia, Polym. Chem. 50 (2012) 2725-2731.

[13] M. Shirai, Y. Yoshida, JP 2004269376, 2004, assigned to Ube Industries, Ltd.

[14] D. Briggs and M. Seah, in Practical Surface Analysis, Ed. Wiley, Chichester, 1990.

[15] D.A. Shirley, Phys. Rev. B Condens. Matter 5 (1972) 4709-47194.

[16] J.F. Moulder, W.F. Stickle, P.E. Sobol, K.D. Bomben, in: J. Chastain (Ed.), Handbook of X-ray Photoelectron Spectroscopy, Physical Electronics, Perkin-Elmer, Eden Prairie, MN, 1992.

[17] L. Armelao, D. Belli Dell'Amico, R. Braglia, F. Calderazzo, F. Garbassi, G. Marra, A. Merigo, Dalton Trans. 28 (2009) 5559-5566.

[18] S.S. Stahl, J.L. Thorman, R.C. Nelson, M.A. Kozee, J. Am. Chem. Soc. 123 (2001) 7188-7189.

[19] A.J. Ingram, D. Solis-Ibarra, R.N. Zare, R.M. Waymouth, Angew. Chem. Int. Ed. 53 (2014) 5648-5652.

[20] J. Le Bras, D.K. Mukherjee, S. Gonzalez, M. Tristany, B. Ganchegui, M. Moreno-Manas, R. Pleixats, F. Henina, J. Muzart, New J. Chem. 28 (2004) 1550-1553.

[21] J.R. Fitch, M. Aslam, D.E. Rios, J.C. Smith, PCT-WO/96-40608 to Hoechst Celanese, 1996.

[22] C. Prabhakar, G. Bakki Reddy, Ch. Maheedhara Reddy, D. Nageshwar, A. Sivalakshmi Devi, J. Moses Babu, K. Vyas, M.R. Sarma, G. Om Reddy, Org. Proc. Res. Dev. 3 (1999) 121-125.

[23] O. Piccolo, A. Verrazzani, US7087548 Assigned to Chemi SpA, 2006

[24] N. Ravasio, F. Zaccheria, P. Allegrini, M. Ercoli, Catal. Today 121 (2007) 2-5.

[25] P. Kraft, J.A. Bajgrowicz, C. Denis, G. Frater, Angew. Chem. Int. Ed. 39 (2000) 2980-3010.

[26] W. Chen, G. Luo, W. Lu, CN 1365962, 2002, assigned to Hangzhou Gelin Perfume Chemistry.

[27] T. Kawanobe, O. Takazawa, M. Amaike, JP 10120674, 1998, assigned to Hasegawa Co.

[28] A.J. Chalk, S.A. Magennis, DE 2627112, 1976, assigned to Givaudan SA.

[29] S. Di Dio, M. Marchetti, S. Paganelli, O. Piccolo, Appl. Catal. A Gen. 399 (2011) 205-210.

[30] S. Paganelli, L. Spano, M. Marchetti, O. Piccolo, Chim. Ind. 87 (2005) 94-98.

[31] K. Bruns, T. Gerke, H. Bahrmann, P. Heymanns, J. Weber, EP 0477747, 1992 (C.A. 117, 14232), assigned to Hoechst.

[32] A.C. da Silva, K. C.B. de Oliveira, E.V. Gusevskaya, E.N. dos Santos, J. Mol. Catal. A Chem. 179 (2002) 133-141.

[33] E.V. Gusevskaya, J. Jimnez-Pinto, Armin Börner, ChemCatChem 6 (2014) 382-411.

[34] W.Q. Du, Z.M. Rong, Y. Liang, Y. Wang, X.Y. Lu, Y.F. Wang, L.H. Lu, Chin. Chem. Lett. 23 (2012) 773-776.

[35] P. Dyson, Dalton Trans. (2003) 2964-2974 